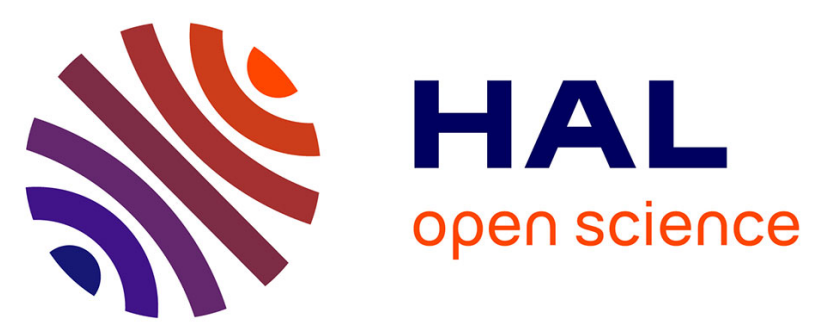

\title{
Indirect Combustion Noise Contributions in a Gas Turbine Model Combustor with a Choked Nozzle
}

\author{
W. Tao, Marek Mazur, M. Huet, Franck Richecoeur
}

\section{To cite this version:}

W. Tao, Marek Mazur, M. Huet, Franck Richecoeur. Indirect Combustion Noise Contributions in a Gas Turbine Model Combustor with a Choked Nozzle. Combustion Science and Technology, 2016, Ninth Mediterranean Combustion Symposium, 188 (4-5), 10.1080/00102202.2016.1139374. hal01312563

\section{HAL Id: hal-01312563 \\ https://hal.science/hal-01312563}

Submitted on 24 Aug 2020

HAL is a multi-disciplinary open access archive for the deposit and dissemination of scientific research documents, whether they are published or not. The documents may come from teaching and research institutions in France or abroad, or from public or private research centers.
L'archive ouverte pluridisciplinaire HAL, est destinée au dépôt et à la diffusion de documents scientifiques de niveau recherche, publiés ou non, émanant des établissements d'enseignement et de recherche français ou étrangers, des laboratoires publics ou privés. 


\title{
INDIRECT COMBUSTION NOISE CONTRIBUTIONS IN A GAS TURBINE MODEL COMBUSTOR WITH A CHOKED NOZZLE
}

\author{
W. Tao*, M. Mazur*, M. Huet** and F. Richecoeur* \\ wenjie.tao@ecp.fr \\ *CNRS, UPR 288 Laboratoire d'Energétique Moléculaire et Macroscopique, Combustion \\ (EM2C), Grande Voie des Vignes, 92295 Châtenay-Malabry, France \\ *Ecole Centrale Paris, Grande Voie des Vignes, 92295 Châtenay-Malabry, France \\ **ONERA - The French Aerospace Lab, F-92322 Châtillon, France
}

\begin{abstract}
Direct and indirect combustion noise sources co-exist in combustors. Direct noise results from unsteady combustion. Indirect contributions are associated to entropy fluctuations convected through flow accelerating devices such as a nozzle. Many analytical and numerical studies on combustion noises have been achieved since the late 1970s yet few experimental studies were carried out to discriminate direct from indirect contributions. An experimental method to compute direct and indirect nozzle transfer functions separately has been developed in our previous work presented in 6th European Combustion Meeting [1]. It consist of measuring the direct and indirect noise transfer functions through simultaneous pressure and temperature fluctuation measurements. The method has already been validated in a well-controlled test bench which generates temperature and acoustic fluctuations without the complexity of combustion. This paper discusses the application of the methodology in a pressurized burner based on simulations of acoustic and entropy fluctuations in the combustion chamber.
\end{abstract}

\section{Introduction}

Noise emission from air transportation has rising concern because of the rapid increase of the air traffic. The main noise contributions to a full scale aeroengine identified by [2] using microphone array techniques include the combustion noise and the exhaust jet noise. While jet noise is the dominant noise at full thrust, combustion noise become the main noise emission at low speed such as landing and taxiing.

It is commonly admitted that combustion noise has two different contributions. Direct combustion noise results from the heat release rate fluctuations in the flame [3] and indirect combustion noise is produced by the acceleration of entropy fluctuations convected by the mean flow due to a pressure gradient [4]. For compact nozzles, analytical solutions obtained by [5] may be used to determine the acoustic pressure reflected and transmitted through the nozzle due to entropy fluctuations. [6] numerically compared the direct and indirect combustion noise in the transmitted noise spectrum through the nozzle and found that indirect noise may be dominant at high ratio of outlet to inlet Mach numbers. The reflected indirect noise also contribute to the acoustic feedback to the upstream combustion process, as experimentally investigated by [7]. More recently [8, 9] considered the indirect noise mechanism in thermoacoustic analysis of a model combustor and concluded that the acoustic addition due to entropy fluctuations may influence the stability of the combustor.

From experimental aspects, one challenging issue is to measure the indirect from the direct transfer function of the nozzle. The difficulty lies in the coherence between the acoustic and entropy fluctuations created due to flame dynamics. As reported by [10], the separation of direct and indirect noises from the correlations between pressure fluctua- 
tions recorded inside and far away from the engine has to suppose that direct flame noise emission and entropy fluctuations are not correlated in the considered frequency domain. Such coherence has been an important error factor in measuring the response of choked nozzle in a combustion chamber during limit cycle [11], and makes it difficult to separate direct and indirect noise contribution through available diagnostics such as pressure and temperature fluctuations measurements. A clever setup as the Entropy Wave Generator (EWG) [12] uses an electrical heating module to produce a hot air column that is transported to the downstream through a convergent-divergent nozzle. However numerical simulations of EWG in supersonic case [13] and subsonic case [14, 15] showed that reflections from EWG outlet and direct noise from electrical heating may both contribute to pressure fluctuations in the discharge flow. So it is necessary to develop experimental strategies aiming at quantifying entropy noise when other noise contributions are present at the same time. However, such work is few documented in the literature.

An experimental method to separate direct and indirect noises has been developed in our previous work presented in 6th European Combustion Meeting[1]. It consists of simultaneous pressure and temperature fluctuation measurements to identify the direct and indirect nozzle transfer functions. The separation method has been applied to an unique acoustically-controlled test bench capable of generating pressure and temperature fluctuations in a subsonic nozzle. It was also numerically validated by the code Sunday (SimUlation of Noise in 1D flows due to fluctuAtions in entropY) developed at ONERA $[15,16]$.

The present study aims at applying the method in a more complicated environment encountered in a high pressure combustor and particularly with a choked condition at the outlet of the combustion chamber. The definition of direct and indirect transfer functions in a compact nozzle and the separation method are first presented. The burner with a choked exhaust nozzle and diagnostics are presented in the next section. Then pressure and temperature evolutions in the burner combustion chamber are simulated by the code Sunday with the knowledge of the nozzle shape as well as the acoustic and entropy waves entering the chamber. Finally, nozzle transfer functions are calculated using the separation method from local pressure and temperature evolutions which are the kind of signals can be measured in real experiments.

\section{Nozzle transfer functions}

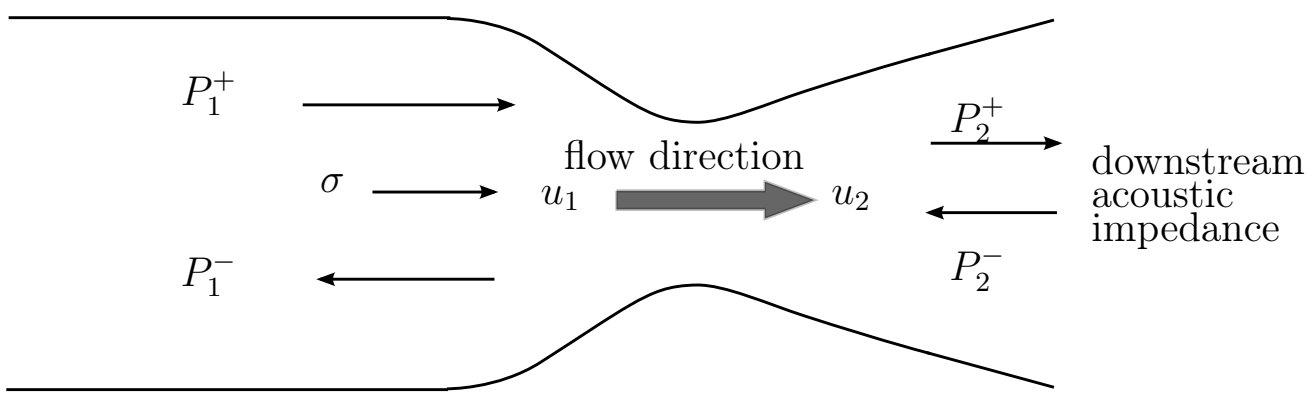

Figure 1: Acoustic and entropy waves propagate in the upstream and downstream a converging-diverging nozzle.

A simple model of the acoustic and entropy waves in a nozzle is illustrated in Fig. 1. The nozzle is submitted to axial acoustic wave $P_{1}^{+}$and entropy wave $\sigma$. In response reflected $P_{1}^{-}$and transmitted $P_{2}^{+}$pressure waves are generated. Usually due to the reflection from boundary conditions downstream of the nozzle, there exists a wave $P_{2}^{-}$in the discharge flow. For subsonic nozzle such disturbances propagate towards the nozzle and 
can also generate direct contribution in the upstream and downstream acoustic field. So waves like $P_{1}^{-}$and $P_{2}^{+}$have direct and indirect contributions from respectively incident acoustic and entropy waves and can be represented by:

$$
\begin{aligned}
& P_{1}^{-}=P_{1 a}^{-}+P_{1 b}^{-}+P_{1 s}^{-} \\
& P_{2}^{+}=P_{2 a}^{-}+P_{2 b}^{-}+P_{2 s}^{-}
\end{aligned}
$$

The subscripts 1,2 designate the regions upstream and downstream of the nozzle, $a, b$ stand for direct contributions due to incoming pressure waves from upstream and downstream side of the nozzle, and $s$ stands for the entropy contribution.

For a compact nozzle, meaning that the length of the nozzle is negligible compared with the wave lengths of acoustic and entropy waves, and if the amplitude of the pressure, velocity and entropy perturbations are within $10 \%$ of respective mean values, one dimensional analytical solution (see Eqs. 3) of the noise generation with respect to the sources (acoustic or entropy) can be found in the famous work of [5].

$$
R_{a}=\frac{P_{1 a}^{-}}{P_{1}^{+}} \quad T_{a}=\frac{P_{2 a}^{+}}{P_{1}^{+}} \quad R_{b}=\frac{P_{2 b}^{+}}{P_{2}^{-}} \quad T_{b}=\frac{P_{1 b}^{-}}{P_{2}^{-}} \quad R_{s}=\frac{P_{1 s}^{-}}{\sigma} \quad T_{s}=\frac{P_{2 s}^{+}}{\sigma}
$$

To separate direct and indirect contributions in nozzle response, we define nozzle transfer functions as:

$$
\begin{array}{ll}
H_{1}=\frac{P_{1 a}^{-}+P_{1 b}^{-}}{P_{1}^{+}} & H_{2}=\frac{P_{2 a}^{+}+P_{2 b}^{+}}{P_{1}^{+}} \\
H_{3}=\frac{P_{1 s}^{-}}{\sigma} & H_{4}=\frac{P_{2 s}^{+}}{\sigma}
\end{array}
$$

Thus $H_{1}$ and $H_{2}$ indicate the reflection and transmission of the perturbing acoustic waves, and $H_{3}$ and $H_{4}$ the generation of indirect noise due to the entropy perturbations.

The analytical values of the above transfer functions in a subsonic flow can be deduced from Marble and Candel's solutions. If the reflection coefficient $R_{L}$ at a distance $L$ downstream of the nozzle is known, it allows to write:

$$
R_{L}=\frac{P_{2}^{-}}{P_{2}^{+}} \cdot e^{-i\left(k_{i}+k_{r}\right) L}
$$

where $k_{i}=\omega / c\left(1+M_{2}\right), k_{r}=\omega / c\left(1-M_{2}\right)$ are the wave number of the progressive and regressive acoustic waves. Then by combining Eqs. 2, Eq. 6 and Marble and Candel's solutions, we obtain expressions 7 and 8 for the total reflected and transmitted waves $P_{1}^{-}$and $P_{2}^{+}$as functions of the incident waves.

$$
\begin{aligned}
& P_{1}^{-}=\left[R_{a}-\frac{R_{L} T_{a} T_{b} e^{i k_{i} L}}{R_{L} R_{b} e^{i k_{i} L}-e^{-i k_{r} L}}\right] P_{1}^{+}+\left[R_{s}-\frac{R_{L} T_{s} T_{b} e^{i k_{i} L}}{R_{L} R_{b} e^{i k_{i} L}-e^{-i k_{r} L}}\right] \sigma \\
& P_{2}^{+}=\left[\frac{T_{a} e^{-i k_{r} L}}{R_{L} R_{b} e^{i k_{i} L}-e^{-i k_{r} L}}\right] P_{1}^{+}+\left[\frac{T_{s} e^{-i k_{r} L}}{R_{L} R_{b} e^{i k_{i} L}-e^{-i k_{r} L}}\right] \sigma
\end{aligned}
$$

These equations show evidently the direct acoustic and entropy contributions on both 
side of the nozzle, from which we find solutions for the transfer functions:

$$
\begin{aligned}
& H_{1}=R_{a}-\frac{R_{L} T_{a} T_{b} e^{i k_{i} L}}{R_{L} R_{b} e^{i k_{i} L}-e^{-i k_{r} L}} \\
& H_{2}=\frac{T_{a} e^{-i k_{r} L}}{R_{L} R_{b} e^{i k_{i} L}-e^{-i k_{r} L}} \\
& H_{3}=R_{s}-\frac{R_{L} T_{s} T_{b} e^{i k_{i} L}}{R_{L} R_{b} e^{i k_{i} L}-e^{-i k_{r} L}} \\
& H_{4}=\frac{T_{s} e^{-i k_{r} L}}{R_{L} R_{b} e^{i k_{i} L}-e^{-i k_{r} L}}
\end{aligned}
$$

These transfer functions depend on the nozzle inlet and outlet Mach numbers as well as the acoustic condition at nozzle discharge. In the particular case of a choked nozzle, the direct and indirect transfer functions $H_{1}$ and $H_{3}$ characterising direct and indirect acoustic feedback to the region upstream of the nozzle are dependant only on the inlet Mach number.

\section{Separation method}

A method for measuring response of a choked nozzle to acoustic and entropy perturbations has already been proposed in [11]. This method, also called the 2M1T method, evaluates the transfer functions (Eqs. 13-14) from the auto- and cross-spectral densities of the incident the entropy wave (designated by $s$ ), the incident the acoustic wave (designated by $a$ ) and the reflected wave (designated by $r$ ).

$$
\begin{aligned}
& H_{1}=\frac{S_{s r} S_{a s}-S_{s s} S_{a r}}{S_{a s} S_{s a}-S_{s s} S_{a a}} \\
& H_{3}=\frac{S_{s a} S_{a r}-S_{a a} S_{s r}}{S_{a s} S_{s a}-S_{s s} S_{a a}}
\end{aligned}
$$

In experimental implementations, the spectral densities are calculated from the auto- and cross-spectral density of simultaneous pressure and temperature measurements due to the relation established for small-amplitude perturbations (noted with '):

$$
\frac{s^{\prime}}{c_{p}}=\frac{T^{\prime}}{\bar{T}}-\frac{\gamma-1}{\gamma} \frac{p^{\prime}}{\bar{p}}
$$

However the 2M1T method is not valid if the acoustic and entropy fluctuations are very coherent because in this case $S_{a s} S_{s a}-S_{s s} S_{a a}=0$. An alternative way to measure the nozzle transfer functions $H_{1}$ and $H_{3}$ is to use the reflection coefficient $\mathcal{R}$ and the complex ratio of entropy wave to acoustic wave $S A=\sigma / P_{1}^{+}$at the entrance of the nozzle following:

$$
\mathcal{R}=\frac{P_{1 a}^{-}+P_{1 s}^{-}}{P_{1}^{+}}=\frac{H_{1} P_{1}^{+}+H_{3} \sigma}{P_{1}^{+}}=H_{1}+H_{3} \cdot S A
$$

In practice the reflection coefficient $\mathcal{R}$ is measured by the three-microphone techniques [17] and the parameter $S A$ can be estimated by computing cross-corellations $S A=S_{a s} / S_{a a}$, following the procedure proposed by [11]. The proposed method is called the diff-R method.

The strategy to calculate the value of transfer functions on each forcing frequency is to compare two operation regimes No.1 and No.2 where the amplitudes of acoustic oscillations are equal but the amplitudes of entropy fluctuations are different. This is 
acceptable if we suppose linear perturbations so that the direct and indirect contributions add straightforward to each other. A simple example is to choose for regime No.1 $|\sigma|>0$ and regime No.2 $\sigma=0$. In the later case, the reflection coefficient is effectively equal to $H_{1}$. Therefore by conserving the same inlet Mach numbers in two conditions, we have:

$$
\begin{aligned}
& H_{1}=\mathcal{R}(\sigma=0) \\
& H_{3}=\frac{\mathcal{R}-\mathcal{R}(\sigma=0)}{S A}
\end{aligned}
$$

Generally in full scale burners it is difficult to have two measurements under the same mean experimental conditions and acoustic amplitudes but different entropy waves. One solution is to consider that the direct transfer function of a compact choked nozzle is well known and can be determined by the inlet flow Mach number. Thus one can use the analytical value

$$
H_{1}=\frac{1-\frac{\gamma-1}{2} M}{1+\frac{\gamma-1}{2} M} ; M \text { is the nozzle inlet Mach number }
$$

together with the measured parameters $\mathcal{R}$ and $S A$ to compute the indirect nozzle transfer function $\mathrm{H}_{3}$.

\section{Experimental setup}

The burner CESAM-HP equipped with a choked nozzle as illustrated in Fig. 2 has been developed at EM2C Lab for investigation of indirect noise. The acoustic boundary condition upstream of the premixing tube is controlled by the impendance control system (ICS) designed by [18], composed of a perforated plate traversed by a bias flow and a Helmholtz back cavity with adaptable length. The bias flow also limits flame flash-back. Lean premixed propane/air swirled flow is generated by tangential injection from the feeding lines into the premixing tube. The combustion chamber is connected to a convergent-divergent nozzle. The nozzle profile has been acoustically optimized to maximize the indirect combustion noise production[19].

Piezo-electric pressure sensors capable of measuring absolute and fluctuating pressure under pressurized condition up to $80 \mathrm{kHz}$ are located in the premixing tube and the combustion chamber. Same sensors are also installed in a pressurized impedance measurement system (PIMS) which is connected to the feeding lines to measure in situ and on-the-fly the acoustic properties by a technique already presented in [20]. The mean gas temperature in the premixing tube and near the entrance of the nozzle are measure by isolated R-type thermocouples that are able to measure temperature up to $1600^{\circ} \mathrm{C}$. The positions of the sensors are illustrated in Fig. 3.

When the burner is running on the operating point in Tab. 1, the measured static pressure in the combustion chamber reaches 2.2 bar and the mean gas temperature near the nozzle approaches $1340^{\circ} \mathrm{C}$. The nozzle is choked in this condition. Measurements of pressure and temperature fluctuations can give access to the acoustic and entropy waves impinging the nozzle and thus are necessary to evaluated the nozzle transfer functions. While the four axially distributed pressure sensors in the chamber are sufficient to capture progressive and regressive acoustic waves, instantaneous temperature in the burnt gas flow is difficult to measure. The power spectral density (PSD) of the sensor in position 2 features several peaks between 98 and $2324 \mathrm{~Hz}$ (Tab. 2). The present study proposes to numerically mimic the experimental test bench and generate numerical pressure and temperature unsteady signals the same mean condition and geometry. The separation method is then applied with local numerical pressure and temperature signals to evaluate 


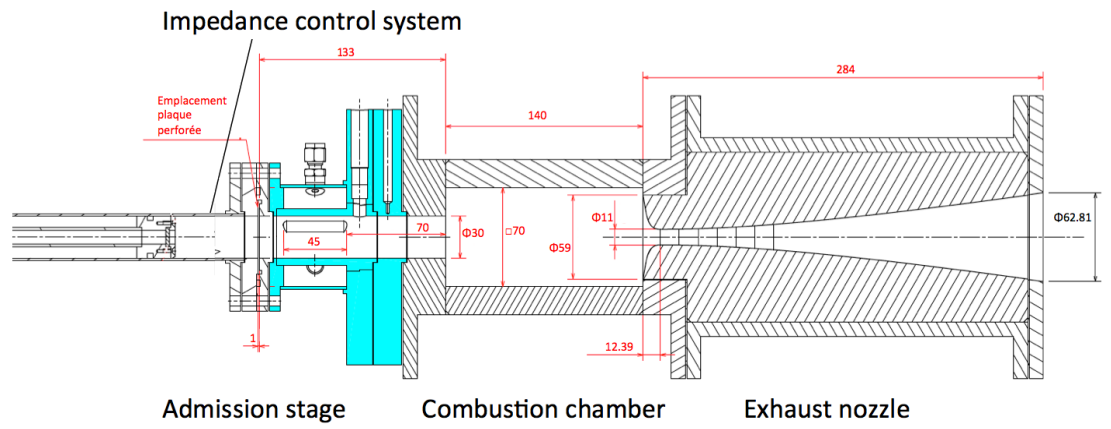

Figure 2: Schematic view of the choked burner CESAM-HP with, from left to right, the impedance control system, the injection tube, the chamber and the converging-diverging nozzle.

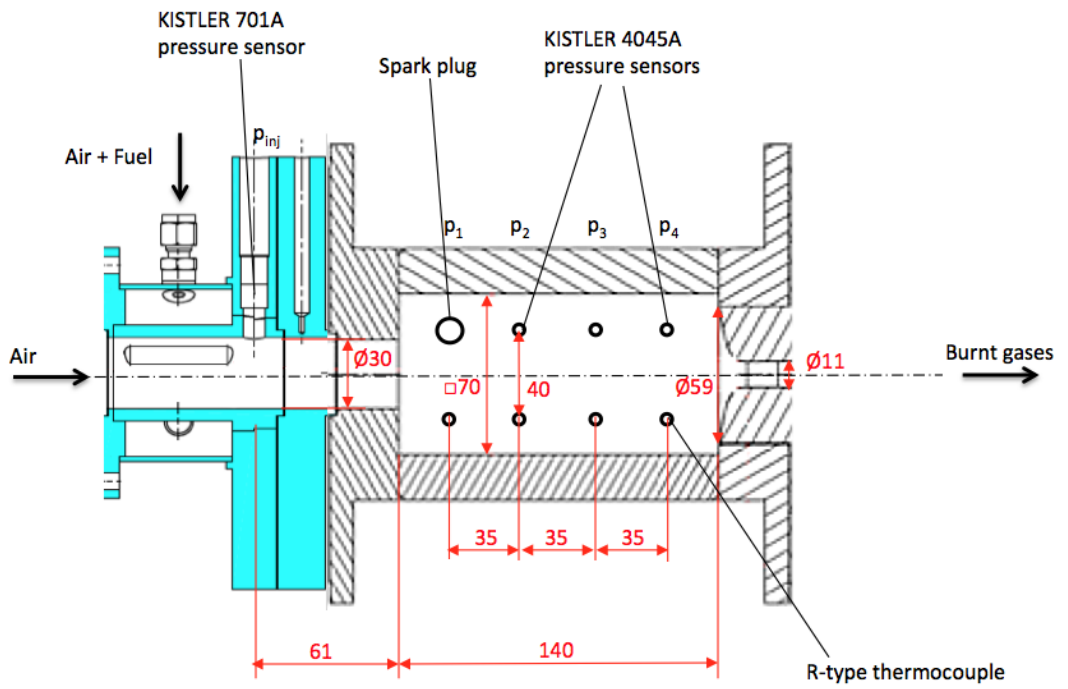

Figure 3: In the combustion chamber, four different pressure measurement positions stand from the injection plane to the exhaust nozzle. 
Table 1: The experimental test bench runs with a lean equivalence ratio, and air mainly entering the chamber tangentially through the injection tube.

\begin{tabular}{c|l}
\hline \multicolumn{1}{c|}{ Property } & Value \\
\hline Name & op13-5-85 \\
Tangential air flow rate $m_{a}$ & $13 \mathrm{~g} / \mathrm{s}$ \\
Tangential fuel flow rate $m_{f}$ & $0.97 \mathrm{~g} / \mathrm{s}$ \\
Axial air flow rate $m_{a x}$ & $5 \mathrm{~g} / \mathrm{s}$ \\
Global equivalence ratio $\Phi$ & 0.85 \\
Mean chamber pressure & $2.2 \mathrm{bar}$ \\
\hline
\end{tabular}

Table 2: The acoustic wave entering the numerical model for Sunday calculation is composed of several harmonic waves.

\begin{tabular}{c|cccccc}
\hline Frequency [Hz] & 98 & 195 & 293 & 381 & 487 & 2324 \\
\hline SPL $[\mathrm{dB}]$ & 169 & 156 & 146 & 141 & 133 & 122 \\
\hline
\end{tabular}

the nozzle transfer functions and compare with analytical solutions. The details for the numerical solver Sunday is present in the next section.

\section{Sunday simulation}

The quasi-one-dimensional non-linear Euler equations of the flow passing through a nozzle are solved with the numerical code Sunday (SimUlation of Noise in 1D flows due to fluctuAtions in entropY). With the knowledge of acoustic and entropy forcing waves and the boundary conditions, it gives the evolution of pressure, velocity and temperature in the flow domain. The calculation domain is composed of the combustion chamber and the nozzle. The combustion chamber is represented by a cavity with a length of $140 \mathrm{~mm}$. The reaction zone is not computed in the calculation. Instead, acoustic and entropy waves are injected at the entrance of the combustion chamber. The suppression of combustion maybe insufficient to accurately represent pressure and entropy fluctuations, but it is not the purpose of using the numerical solver, which is to generate the representative pressure and temperature signals related with the nozzle to validate the separation method. However, it maybe interesting to use tools like the flame describing function [21] to determine acoustic and entropy waves eminent from the flame in further studies.

The incident acoustic wave is represented by the superposition of harmonic waves at frequencies and amplitudes corresponding to the peaks identified in the PSD spectrum of the pressure sensor on position 2 which are summarized in Tab. 2. Although there are not yet experimental informations on entropy fluctuations in the flow, but it is assumed that entropy spots are transported at the bulk flow velocity towards the nozzle and that the characteristic convection wavelength of entropy spots equals approximately the chamber length. The frequency of the entropy wave is estimated by this way at $105 \mathrm{~Hz}$. The nondimensional amplitude of the entropy wave $\sigma$ is set to 0.05 , which refers to a moderate estimation that the amplitude of the temperature fluctuations weights $5 \%$ of the mean temperature.

Finally the acoustic upstream boundary condition is characterized by $u^{\prime}=0$ to mimic the wall-type condition at the entrance of the chamber while in the numerical calculations acoustic and entropy waves are allowed to leave the domain without much reflections. The calculation is implemented for simultaneous acoustic and entropy wave forcing the nozzle. Signals on the four sensor positions in Fig.3 are recorded at $20000 \mathrm{~Hz}$ during 5 seconds. 
The obtained fluctuations of pressure, velocity and temperature on the sensor position 2 are normalised by their mean values $(\bar{p}=2.2 \mathrm{bar}, \bar{T}=1612 \mathrm{~K}$ and $\bar{u}=8.7 \mathrm{~m} / \mathrm{s})$ and are traced in Fig. 4. It is noted that the fluctuating properties all oscillate within $10 \%$ of the mean values (the same on the other three positions) so that the separation method can be used to evaluate the indirect nozzle transfer function $H_{3}$.

\section{Results and discussions}

When treating the simulation signals, the incident acoustic and entropy waves are supposed unknown. Combustion noises are only characterized through the pressure signals in the combustion chamber. Firstly 2048 samples are used to compute the PSD of pressure and temperature fluctuations on position 2, which are shown in Fig. 5. Five distinct peaks with SPL higher than $100 \mathrm{~dB}$ : 98, 195, 293, 381 and $488 \mathrm{~Hz}$ are observed (all corresponding to the input acoustic wave of Sunday calculation). By the same spectral analysis it is found that temperature fluctuations have maximum amplitude on $107 \mathrm{~Hz}$ (which differs only slightly from that of the input entropy wave $105 \mathrm{~Hz}$ ). The frequency resolution of the spectral analysis here is about $10 \mathrm{~Hz}$, so it is probable that direct and indirect noise contributions are most correlated on $107 \mathrm{~Hz}$. Moreover there is a distribution of multiple peaks in the pressure spectrum around $2324 \mathrm{~Hz}$, and the frequency difference between two adjacent peaks is equal to $107 \mathrm{~Hz}$. There maybe a coupling of acoustic and entropy modes but more work needs to be done in order to clarify this phenomenon. The nozzle transfer function $\mathrm{H}_{3}$ is evaluated on the identified frequencies smaller than $500 \mathrm{~Hz}$.

In the next step, it is necessary to evaluate the coherence between acoustic and entropy waves in order to chose a proper method to calculate the nozzle transfer function. To do so the coherence factor between the incident waves $C_{a s}=\left|S_{a s}\right|^{2} /\left(S_{a a} S_{s s}\right)$ is computed from the pressure signals on position 3 and 4 , and the temperature signal on position 4 , the maximum of which is also found on $107 \mathrm{~Hz}$ in Fig. 6. As a result, the 2M1T method (see Eq. 14) is used to calculate the indirect nozzle transfer function $H_{3}$ on the frequencies listed in Tab. 2 on which $C_{a s}$ almost vanishes. At $107 \mathrm{~Hz}$, where $C_{a s}=1$, the reflection coefficient $\mathcal{R}$ and the complex ratio $S A=\sigma / P_{1}^{+}$are evaluated. The value of $H_{3}$ is then calculated according to Eq. 18 by using the analytical solution in Eq. 19 with $M=0.01, \gamma=1.29$ (given by Sunday). For comparison purpose the value of $H_{3}$ at $107 \mathrm{~Hz}$ is also computed by the $2 \mathrm{M} 1 \mathrm{~T}$ method.

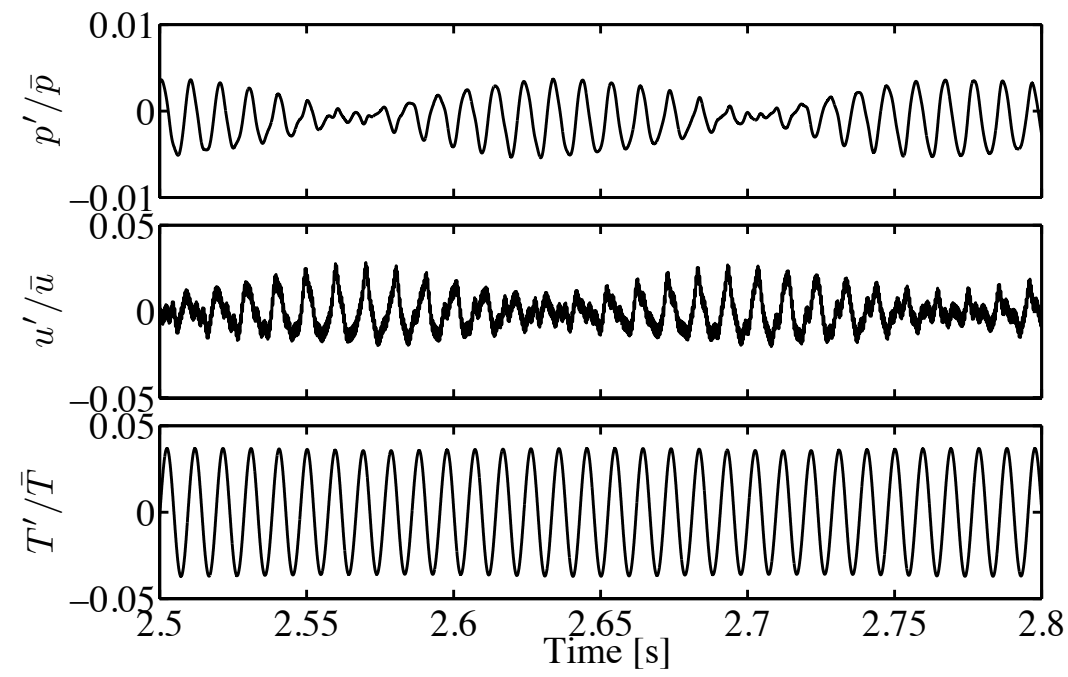

Figure 4: Sunday simulation time signals. Top: Pressure fluctuations. Middle: Velocity fluctuations. Bottom: Temperature fluctuations 


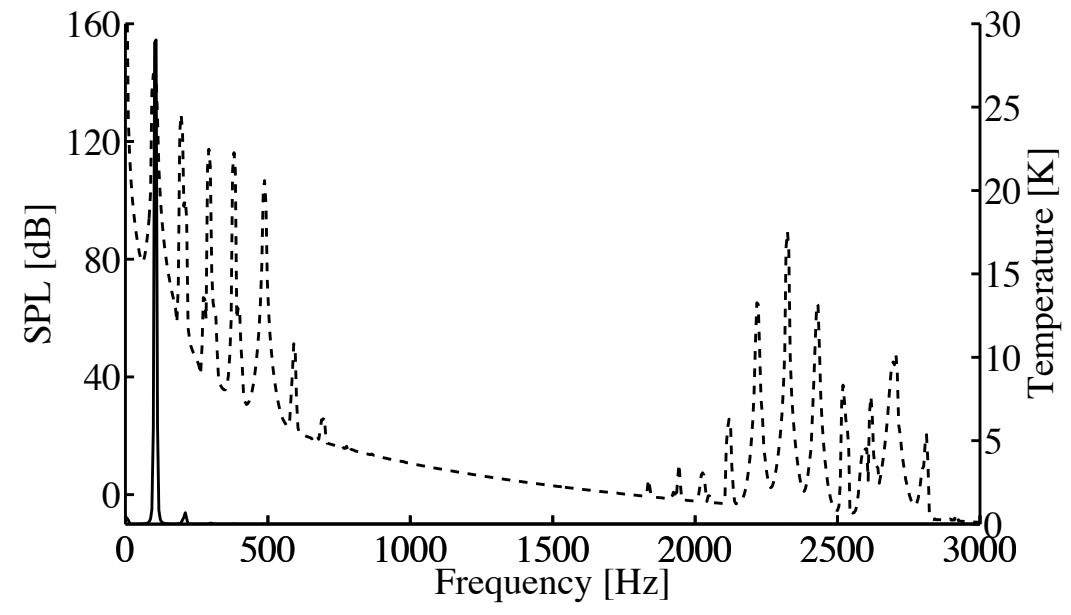

Figure 5: Power spectrum of numerical pressure and temperature fluctuations on position 2. Left axis and dashed-line: Pressure. Right axis and black-line: Temperature.

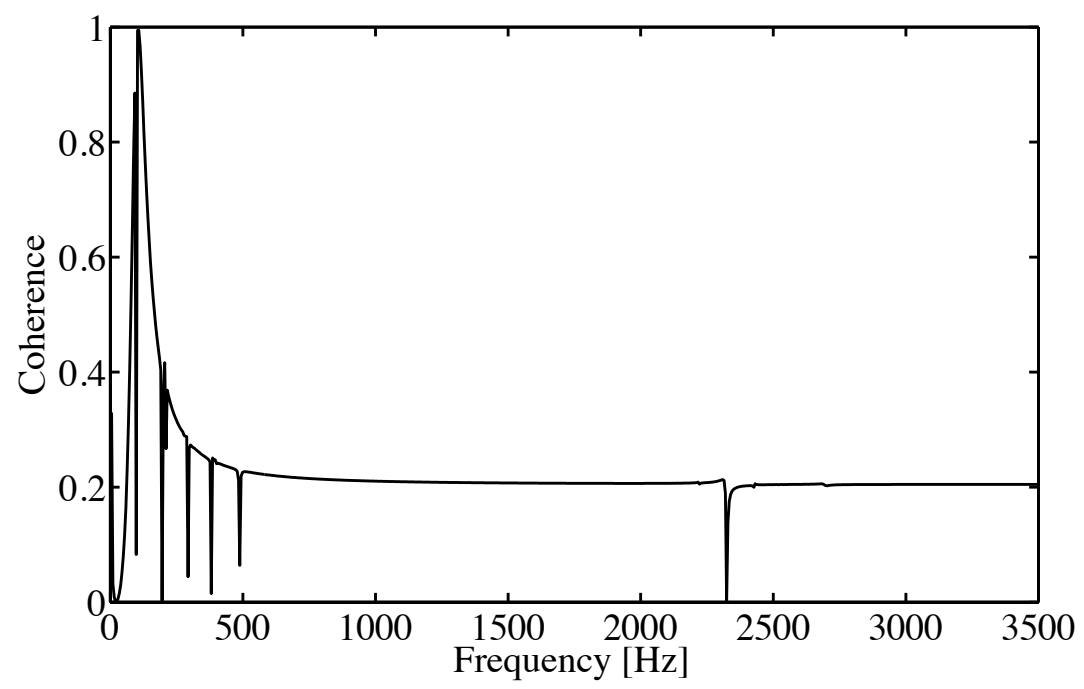

Figure 6: Coherence factor of incident entropy and acoustic waves. 


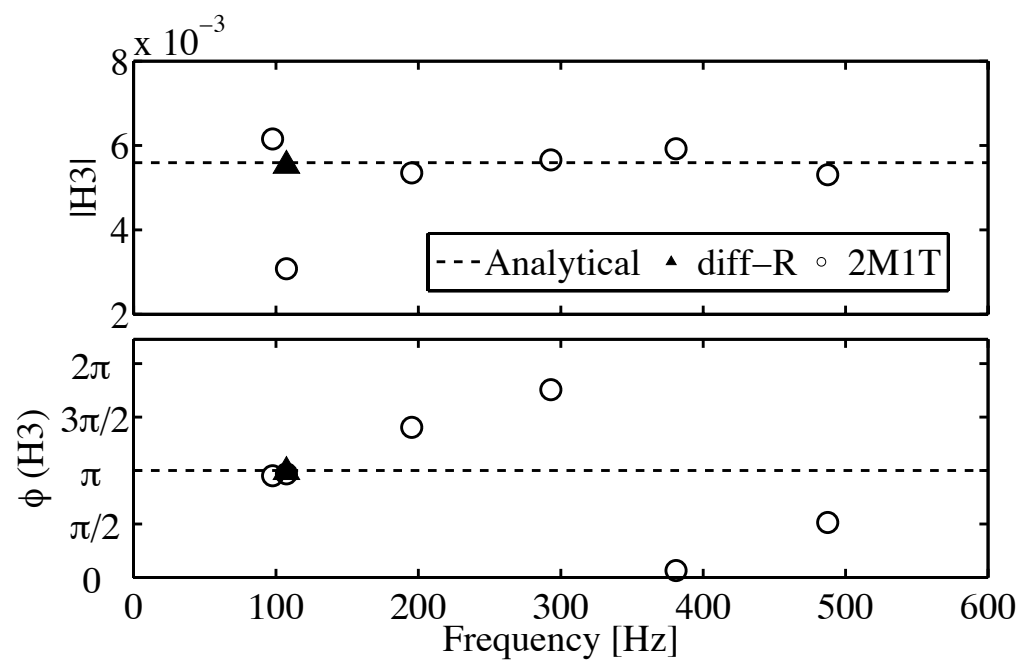

Figure 7: Indirect nozzle transfer function calculated by analytical compact nozzle solution (dashedline), the diff-R method on $107 \mathrm{~Hz}$ (black triangle) and the 2M1T method on 98, 107, 195, 293, 381 and $487 \mathrm{~Hz}$ (empty circle).

The results of the indirect transfer function $\left(H_{3}\right)$ from the analytical compact nozzle solution, the 2M1T method and the diff-R method are plotted in Fig. 7. The absolute value of $\mathrm{H}_{3}$ calculated by the $2 \mathrm{M} 1 \mathrm{~T}$ method is close to the analytical compact nozzle solution within $\pm 10 \%$ of relative errors, except on $107 \mathrm{~Hz}$. And unlike the constant phase in analytical compact nozzle solution, the phase value of $H_{3}$ calculated from the $2 \mathrm{M} 1 \mathrm{~T}$ method is linearly dependant on the frequency. But the value on $107 \mathrm{~Hz}$ is correctly calculated using $\mathcal{R}$ and $S A$.

To conclude, the indirect nozzle transfer function has been measured from numerical temperature and pressure fluctuations that are solved by the code Sunday with representative acoustic and entropy forcing waves in the CESAM-HP burner. It has been shown the diff-R method is able to measure correctly the indirect nozzle transfer function when acoustic and entropy wave are most correlated. In some burners the correlation between acoustic and entropy fluctuation may be broke down as they propagate towards downstream due to turbulence, but it is more likely to sustain in the CESAM-HP burner since the combustion chamber is relatively short. Therefore it is promising to use the diff-R method to evaluate the indirect combustion noise contributions in the combustion chamber if access to the temperature fluctuations are allowed.

\section{Conclusion}

This paper discusses the application of an experimental method to measure the indirect nozzle transfer function in a gas turbine model combustor with a choked nozzle. First the transfer functions of a compact nozzle are defined and their analytical solutions have been deduced from a former work by [5]. Then the separation method diff-R has been presented, which uses the link between the transfer functions with the nozzle reflection coefficient $\mathcal{R}$ and the complex ratio $S A$. The study on the possibility to use the diff-R method in the CESAM-HP burner with a choked nozzle is based on numerical signals generated by the code Sunday. To do so, characteristic acoustic and entropy waves have been injected to the calculation domain composed of the combustion chamber and the nozzle. From the pressure and temperature evolutions in the combustion chamber given by the code Sunday, the diff-R method has been proofed capable of measuring the indirect 
nozzle transfer functions when entropy and acoustic waves are very coherent. In the future it maybe interesting to characterize acoustic and entropy waves impinging to the nozzle by the flame dynamics. This approach is likely to provide the numerical solver Sunday with more information on the forcing waves and thus more evidence for the application of the diff-R method.

References

[1] Tao, W., Schuller, T., Ducruix, S., Richecoeur, F., "Development of a noise generator dedicated to direct and indirect combustion noise separation", European Combustion Meeting (2013).

[2] Hoch, R., Hawkins, R., "Recent studies into Concorde noise reduction", AGARD Conference Proceedings, Noise Mechanism (1973).

[3] Candel, S., Durox, D., Ducruix, S., Birbaud, A.L., Noiray, N., Schuller, T., "Flame dynamics and combustion noise: progress and challenges", International Journal of Aeroacoustics 8:1-56 (2009).

[4] Strahle, W., "On combustion generated noises", Journal of Fluid Mechanics (1971).

[5] Marble, F.E., Candel, S.M., "Acoustic disturbance from gas non-uniformities convected through a nozzle", Journal of Sound and Vibration 55:225-243 (1977).

[6] Leyko, M., Nicoud, F., Poinsot, T., "Comparison of Direct and Indirect Combustion Noise Mechanisms in a Model Combustor", AIA A Journal 47:2709-2716 (2009).

[7] Eckstein, J., Freitag, E., Hirsch, C., Sattelmayer, T., "Experimental Study on the Role of Entropy Waves in Low-Frequency Oscillations in a RQL Combustor", Journal of Engineering for Gas Turbines and Power 128:264 (2006).

[8] Goh, C.S., Morgans, A.S., "Phase prediction of the response of choked nozzles to entropy and acoustic disturbances", Journal of Sound and Vibration 330:5184-5198 (2011).

[9] Goh, C.S., Morgans, A.S., "The Influence of Entropy Waves on the Thermoacoustic Stability of a Model Combustor", Combustion Science and Technology 185:249-268 (2013).

[10] Muthukrishnan, M., Neale, D.H., Strahle, W.C., "Separation of Hydrodynamic, Entropy, and Combustion Noise in a Gas Turbine Combustor", Aiaa Journal 16:320-327 (1978).

[11] Hield, P.A., Brear, M.J., "Comparison of Open and Choked Premixed Combustor Exits During Thermoacoustic Limit Cycle", AIAA journal 46:517-526 (2008).

[12] Bake, F., Richter, C., Mühlbauer, B., Kings, N., Röhle, I., Thiele, F., Noll, B., Rôhle, I., "The Entropy Wave Generator (EWG): A reference case on entropy noise", Journal of Sound and Vibration 326:574-598 (2009).

[13] Leyko, M., Nicoud, F., Moreau, S., Poinsot, T., "Numerical and analytical investigation of the indirect combustion noise in a nozzle", Comptes Rendus Mécanique 337:415-425 (2009). 
[14] Durán, I., Moreau, S., "Analytical and numerical study of the entropy wave generator experiment on indirect combustion noise", 17th AIAA/CEAS Aeroacoustics Conference, ... pp. 1-17 (2011).

[15] Giauque, A., Huet, M., Clero, F., "Analytical Analysis of Indirect Combustion Noise in Subcritical Nozzles", Journal of Engineering for Gas Turbines and Power 134:111202 (2012).

[16] Huet, M., Giauque, A., "A nonlinear model for indirect combustion noise through a compact nozzle", Journal of Fluid Mechanics 733:268-301 (2013).

[17] Chung, J.Y., Blaser, D.A., "Transfer function method of measuring in-duct acoustic properties. I. Theory", Journal of the Acoustical Society of America 68:907-913 (1980).

[18] Tran, N., Ducruix, S., Schuller, T., "Passive Control of the Inlet Acoustic Boundary of a Swirled Burner at High Amplitude Combustion Instabilities", Journal of Engineering for Gas Turbines and Power 131:051502 (2009).

[19] Giauque, A., Huet, M., Clero, F., Ducruix, S., Richecoeur, F., "Thermoacoustic Shape Optimization of a Subsonic Nozzle", Journal of Engineering for Gas Turbines and Power 135:102601 (2013).

[20] Lamraoui, a., Richecoeur, F., Schuller, T., Ducruix, S., "A Methodology for On the Fly Acoustic Characterization of the Feeding Line Impedances in a Turbulent Swirled Combustor", Journal of Engineering for Gas Turbines and Power 133:11504 (2011).

[21] Noiray, N., Durox, D., Schuller, T., Candel, S., "A unified framework for nonlinear combustion instability analysis based on the flame describing function", Journal of Fluid Mechanics 615:139 (2008). 